\title{
Plant Genetic Resources and its Global Contribution
}

\author{
Kazuo N. Watanabe* and Masaru Iwanaga** \\ * Department of Biotechnological Sciences, Kinki University, Uchita, Wakayama, Japan \\ (Correspodence; Kazuo N. Watanabe, Fax, 81-736-77-4754) \\ ** International Plant Genetic resources Institute (IPGRI), Rome, Italy
}

\begin{abstract}
Plant genetic resources (PGR) have been contributed to the daily life of the people in the world through the domestication of and civilization with them. PGR should be regarded as the essential subjects, the same as water, air, and soil which are the important components of the global environment. Thus, PGR can be deteriorated or lost easily unless we pay an extra-caution to live with them.

In an old time, more numbers of plant species have been used for food, feed, fiber, remedy, energy, construction, manufacturing and/or environmental protection compared with the limited number of species used at present. PGR have been supported the development of the traditional knowledge and culture, in contrast which is now diminishing very rapidly with PGR.

With the modern agriculture supported by the plant breeding, many of crop species have been further modified for the needs of human beings. On the other hand, an extensive use of particular species and cultivars have been caused the decrease in the diversity of the plant species for use and for conservation in nature.

While science and technology are further being developed, there is constant increase in possibility to enhance the potential capability of crop species for synchronizing sustainability and productivity. On the other hand, without the contribution of PGR as the platform for the application on such science and technology, there would not be much future on the outcome of the applications of the modern science and technology. Learning from the past, the rejuvenation of traditional knowledge and cultural information, and the exploitation of the under-utilized PGR from elsewhere, should alleviate the diverse spectra of pitfalls confronting the needs of human beings.
\end{abstract}

\section{History: Humans always have been lived with the diverse plant genetic resources}

It is estimated that Plant kingdom confers about 600,000 species, and the half of the number falls in angiosperms to which many of agricultural species belong [1]. It should also be noted that around one-third of the total number belong to alga and its alliance, and many of them have not been exploited well, which may have a vast potential to be used as futuristic food, medicinal materials, and innovative agents such as bioremediation [2].

One of the first identified plant genetic resources (PGR) as food in the literature could be apples in the Garden of Eden in the Bible, which was sinfully harvested by Eve with Adam. Many resemble cases shall be seen in any other sacred books, and the PGR have been always contributed to human beings for their prosperous development and civilization through its domestication and cultivation processes and the resulting products [2, 3]. Thus, humans have been exploited a diverse plant genetic resources for various uses and have been lived with them.

At the gatherer time of the human history, an average human individual used to consume food materials from thousands of species of plants and animals annually [2, 4]. It should be noted that the majority of species were plants. Humans really depended on the plant derived food materials since then. Also at the time, many plant species had been domesticated and introduced for cultivation which have led to stable community development.
Prosperous civilization was fostered by the cultivation of staple crops such as rice, wheat, corn and potato and by the frugal uses of forests. On the other hand, average individuals of today depends on food materials with an average of two hundred plant species, and the forests are slashed and burnt elsewhere [5]. With the modern development of plant breeding and unbalanced agricultural systems aimed for productivity, only a few cultivars are intensively used instead of a number of landraces with diverse genetic backgrounds [6]. A severe disease or pest infestation could wipe out these modern cultivars due to their narrow genetic flexibility [7]. It should also be pointed out that extensive sacrifice of the forests for modern industrialization is hardly irreversible, and now humans are facing serious global environmental problems. We are under vulnerable situation to keep the development of humans and the sustainability of the earth due to our own sake of the global environmental change. Where have gone the genetic and subsequent dietary diversity with PGR and the abundant forests, and how do we do for future?

\section{Living with plants for future harvest}

A series of short narrative paragraphs are given in the below to highlight the importance of PGR in the survival and prosperous growth of human beings harmonizing with the mother earth. The original text is quoted from "Future Harvest" campaign by Consultive Group on Inter- 
national Agricultural Research (CGIAR) [8].

Terrorism forced Marin Cirilo and his wife Lucia to flee their farm in the Peruvian Andes and to settle their young family in the Amazon basin. There was an oil processing plant nearby and land was cheap, so they began cultivating five hectares of oil palm and started their new life.

Too often, the public and policymakers think of research as the means to produce a tastier tomato or an earlier-maturing bush bean. The truth is that improved PGR consequently for more suitable agriculture for many needs, as a result of research, has much wider social benefits-peace, prosperity, environmental protection, health, and the alleviation of human suffering. Future Harvest promotes knowledge about these links.

(1) Food for peace: Conflict over shortages of food, water, and land, particularly within and between poor nations, afflicts the world. The results can be starvation and migration, such as the Cirilos' movement to the Amazon frontier. Research, for example, to improve the use of genetic resources, makes it possible to grow more food on existing farmland more efficiently and using less water, and can help to head off such conflicts.

(2) Food for growth: In countries where agriculture is the basis for economic growth, agricultural research is a bridge to new markets. Lower food prices and shared prosperity can foster social advancement. The community-owned processing plant that buys Marin Cirilo's palm nuts is one link in a worldwide economic chain. With money from palm nuts, the Cirilos buy goods from other countries.

(3) Food for the earth: By increasing yields, making better use of genetic resources, and allowing farmers to grow crops more sustainably, science provides alternatives to the destruction of forests, soil, water supplies, and wildlife. Research can help the Cirilos to make adequate income without needing to slash and burn their way deeper into the forest.

(4) Food for health: The three worst killers of children-malaria, diarrhea, and respiratory infection-are all linked to malnutrition. The Cirilos know that when their children are born, hunger will make them susceptible to disease. Programs focused on the health of people in the developing world, especially children, must be linked to the food people eat.

(5) Food for people: Obviously, humanity cannot survive without food. But we often overlook the fact that research to sustainably increase food production can also bring economic growth and higher incomes for poor farmers. Better living standards reduce poverty and hunger and contribute to stabilizing population growth and environmental protection. Agricultural research helps to keep people like the Cirilos healthy, productive, and prosperous as they build their new lives.

Sustainable development and global security in the twenty-first century will be possible only when people recognize that the world's food supply, and the land, water, and biological diversity that make that food supply possible, exist in precarious balance. Research on plant and agricultural sciences is a key to maintaining this balance, which is essential to human harmony, growth, and health $[9,10]$.

\section{Present social and technical issues associated with PGR conservation and uses [11]}

\subsection{National policy and institutional framework}

The Convention on Biological Diversity (CBD), which has been ratified by numerous countries, gives much importance to biotechnology associated with the conservation and utilization of plant genetic resources, and considers it as a means to enhance sustainable use and equitable sharing of its benefits. Hence it is appropriate to discuss the current situation as well as some future perspectives on this subject. Transfer of technology associated with PGR, including biotechnology, has been a key political issue for developing countries. A successful application of biotechnology at practical levels (National Programs), an institutional framework and national policies favorable to the practical application of biotechnology are needed. The individual characteristics of the world's flora and fauna are the basis of biotechnology. Individually, they produce the molecules on which biotechnology depends. These molecules have no other source [12].

It must be recognized that only diversity can allow sustainability. Only diversity can support social and economic systems to flourish, which allow the poorest to meet their food and nutritional needs as well as cultural diversity to flourish the world [13]. The biological resources of each country are important, but not all countries are equally endowed. The relative values of various resources are different. In general, it is well known that a few countries lying within the tropics and subtropics account for a very high percentage of the world's biodiversity. The CBD became an international agreement on 29 December 1993 when more than 30 countries ratified it. Issues related to technology transfer, funding mechanisms, intellectual property rights (IPR) and access to genetic materials have been discussed at various levels. There are strong proponents of IPR for genetic resources and their products as well as strong opposition to them at the conceptual level $[14,15]$. The CBD encourages both access to and transfer of technology (including biotechnology) among nations, especially with developing countries. Access and transfer of any technology shall be consistent with the adequate and effective protection of intellectual property rights. Necessary policy measures shall be taken up to access and transfer technology on mutually agreed terms, as should plant genetic resources. Such measures shall assist joint development and transfer of technology for the benefit of both governmental institutions and the private sector organizations in developing countries. The major problems that have been identified for transfer of technology as well as their adoption in the recipient country are: access to capital, human resources and support services; intellectual property rights; regulatory issues such as biosafety and exchange of information and knowledge; environmental concerns and transaction costs [10].

The CBD encourages countries to take legislative, administrative or policy measures to handle issues related 
to biotechnology and the sharing of its benefits on a fair and equitable basis. Countries may be required to set up appropriate procedures (such as codes of conduct) in the field of the safe transfer, handling and use of any living modified organisms resulting from biotechnology that may have an adverse effect on the conservation and sustainable use of biological diversity. National committees may be set up to discuss and recommend the necessary measures. The need for providing any available information about the use and safety regulations in handling such organisms (biosafety regulations), as well as available information on the potential adverse impact of the specific organisms is recognized.

Broadly speaking, benefits of biodiversity for the biotechnology industry can be twofold. Firstly, biodiversity significantly lowers the research and development costs of the industry since it serves as a highly productive in-situ-stock of genetic material [16]. The potential uses of biotechnology for conservation are many and one of the most important is in the context of making conservation and use of plant genetic resources cost-effective $[1,9,17-$ 21]. For the implementation of the CBD, it is essential that the benefits overtake costs and thus conservation becomes attractive to policy makers. Additionally, biodiversity represents insurance for agriculture because it diminishes the risks of productivity variations as it can rely on many instead of only a few cultivars $[2,3,7,22-25]$. The preferential technology, including biotechnology, basically means that the developing countries will at least partially be able to circumvent license fees without risking any sort of retaliation [26-28]. This arrangement may be looked at as an essential mechanism for donor support to biodiversity conservation [29]. For fairly detailed discussion of several issues related to technology transfer, national policies, areas of application of biotechnology, etc., see Altman and Watanabe [10].

\subsection{Public awareness and intellectual property rights (IPRs)}

Among the international discussions, the nationalism on PGR, especially the protection of IPRs such as the patenting of the plant varieties has been a global and complicated concern which cannot be sorted out simply among related parties and nations [29]. However, it seems that the importance of the value of PGR is not well recognized by the public compared with the recognition of other natural resources such as water, air and energy; The Japanese public is no exception [30]. PGR is not only the components of important natural resources, but also has strong links with environmental conservation matters. For example, the tropical forests consist of a complex of plant species, which are essential for the conservation of ecosystems and self-remediation of the ecosystems by plants [23]. Thus, the value of PGR is exquisite for the present and the future $[2,9,17,21,23,24]$.

In contrast to the overwhelming interest among various sectors and individuals in Japan in the initial Environmental Summit held at Rio de Janeiro in 1992 which included the conservation and sustainable use of biological diversity, there is very little attention paid to the on-going meetings of the Convention of Parties (COP) associated with the CBD [32]. On May, 1998, COP-4, the fourth meeting of the COP, was held at Slovakia. However, it is a pity that there was not much participation by Japanese groups compared with the Rio Summit, although one fifth of the proposed budget which is equivalent to US $\$ 50$ million has been pledged by Japanese government to CBD [33].

A specific example of the current situation on the IPR with PGR, with respect to profit-oriented interests of specific groups follows. Bolivian quinoa was patented by US professors: Quinoa (Chenopodium quinoa) is a small grain species which is rich in protein, and is very common and important in the diet for the people of the Andean region. In developed countries including Japan, quinoa is used for diet food in regular markets and is becoming economically important. The use of F1 hybrids to make cultivars has been considered, and the production of seeds for these cultivars has been profitable in the US and European seed business. Professors at the University of Colorado patented the male sterility trait derived from Bolivian quinoa, Apelawa variety for F1 seed production in 1994 (US Patent 5304718) [34]. This patenting has damaged the traditional use, production and ownership of Andean users, because of the potential of forbidding and fining the exportation of the quinoa variety from the Andean region to USA as the infringement of the US patent.

The above type of nonsensical patenting issues and extremely biased protection of IPRs are associated with the following undigested matters in societies [9, 17, 31].

(1) Lack of number of legal specialists: There are few patent attorneys with in-depth knowledge on PGR and biotechnology compared with the actual needs. In the case of Japan, there are less than ten patent attorney offices which can handle the legal and technical matters associated with PGR and biotechnology. Also, the total number of patent attorneys in Japan is extremely small in contrast to the skyrocketing increases in IPR protections. In a similar way, not many exclusive specialists are available in plant protection laws [35]. Human resources development in this area is essential in winning or even protecting the national interest and industrial development.

(2) Bioethics: The recognition of the ownership of and benefit sharing from the PGR must be considered before discussing the legal matters. The concept of equitable IPR should be the key issue for making a globally fair distribution of benefits from the PGR. This should not be recognized only by scientists, but also by the general public as to their rights as the potential recipients of the benefits from PGR.

(3) Public awareness: The public enlightenment on the value and rights towards PGR should be widely introduced especially in the industrial sectors which should consider returning the contribution back to the parties/communities where the beneficial PGRs originated. This is not only from the views of benefit sharing but also from the philanthropic view which must be considered.

The understanding of the above subjects will lead to working with the nations/parties which can have strong chain on the ownership of the PGR [36]. Now, many 
countries with rich diversity and/or are the origin of the species of interest require legal documentation to access PGRs; Germplasm Acquisition Agreement (GAA) and Material Transfer Agreement (MTA) together with Export Permit/Certificate should be prepared in any international transaction in the movement of the PGR. Thereby, the parties which do not follow the procedures will be in legal violation internationally as well as accused publically. However, due to the slow process of the negotiation of the international treaty under $\mathrm{CBD}$, it may be more difficult in the short run for the physical movement and use of PGR in plant breeding or other associated disciplines as many countries become sensitive and protective on the matter. An immediate consensus is desirable, however, in the reality of international dealing, this will not happen. The international political turmoil and extreme profit orientation by the private sector on PGR may contradict the efforts towards alleviating the food and population problems in the 21 st century [37].

\subsection{Conservation of plant genetic resources in gene- banks}

The conventional conservation of PGR has been conducted in situ by local communities and small-scale traditional farmers [1, 17]. In contrast, the genebanks also have been engaged in preserving collections ex situ [7, $18,25]$. Here, biological aspects of the preservation of the PGR at genebanks shall be highlighted for the many species which need more basic information.

\section{A. True seed propagated species}

The following subjects are important for further research [20];

(1) Physiology on flowering and seed propagation;

(2) Physiology of seeds for long term storage;

(3) Population size and change in allelic frequencies on rejuvenation of seed generations; and

(4) Increasing chance in recalcitrant species, especially in the tropics [38];

Especially to determine the amount of seeds to be preserved, these two issues also have importance: (1) Duration of the period of seed storage in each seed generation and statistical probability on viability and (2) general genetic diversity and preservation of specific alleles of interest [19]. Under common recommendations, a large amount of seeds per accession shall be maintained, on the other hand, an enormous number of accessions should be preserved at a genebank, so critical mass for the maintenance of each accession should be another factor for the PGR preservation at a genebank. Unfortunately, the reality of the genebanks is far from the desirable condition due to the shortage of sufficient financial back-up. At many genebanks, there could be genetic erosion taking place due to managerial factors principally attributed to the insufficient funding supports. An example of typical crisis is the present situation at the N. I. Vavilov Research Institute for Plant Industry at St. Petersburg, Russia, which used to be the top-notch PGR genebank. However, now it is facing financial crisis, consequently there is danger of the loss of precious PGR collections [31].

\section{B. Vegetatively propagated and/or perennial species}

The following subjects shall be further studied for more effective management of the clonally maintained accessions [17, 31].

(1) Rooting capacity in woody species and epiphytes;

(2) Reduction of somaclonal variation in in vitro preservation;

(3) Duplicates identification;

(4) Genotype independent tissue culture methods; and

(5) Cryopreservation, especially for tropical species.

\subsection{Conservation and use of the plant genetic resources towards sustainable industrialization with biotechnolo- gy applications}

The primary use of the PGR in the industry is for the production of basic materials. Planned production in plantations and agriculture fields would be less damaging than collection/harvest from natural reserves, although as yet serious environmental concerns about pesticide uses and erosion exist. As well as agricultural plant species, it should be recognized that a gradual shift from slash-andburn of the tropical forests to a scheduled and systematic production has been taking place. This is based on mass production of propagules through the application of micropropagation to the industrially interesting species and extensive public education of the in situ conservation and use of natural forests $[1,23]$. On the other hand, only a limited number of species can be employed by such a system due to an unavailability of specific technology relating to particular species $[9,17,31]$. Also it shall be remarked that an extreme bias of the selection of or monoculture of cultivars/species always results in genetic erosion, thus, a strategic use of the technologies should be accompanied by sustainable uses of PGR harmonized with the genetic conservation.

With the advancement of basic research and development in the plant sciences and technologies, the following categories should enhance the conservation and use of the PGR $[11,31]$.

(1) Mass propagation by tissue culture for conservation.

(2) Photo-autotrophic micropropagation on a large scale for industrial propagule production.

(3) Immunological or molecular biological tools for detection of plant pathogens and pests in plant quarantine and genebanks. A measure for the quality of commercial propagules.

(4) Detection of environmental toxins/pesticides in in situ conservation.

(5) Molecular markers for the evaluation of genetic diversity and genetic erosion $[39,40]$.

(6) Molecular biological approaches to isolate and utilize plant genes in genetic engineering.

The above categories are being used for some specific cases, however, it is needed to accelerate the basic research for tropical plant species which have a lot of missing information and require refinement of the technology application.

Further exploitation by basic research should be encouraged in the following areas for systematic industrial utilization of PGR [31]; 
(1) Extensive survey of the genetic diversity and specific chemical substances of industrial interest other than major crop species;

(2) Survey of the relationships between the pesticide residues and conservation of PGR, and development of agrochemicals with low residue and low toxicity as often landraces and wild species are more sensitive to agrochemicals than modern cultivars;

(3) Low cost and low profile tissue culture system for small scale industry;

(4) Mass production methods for elite clones for large scale industrial purposes instead of slash-and-burn type uses.

(5) Preservation methods for recalcitrant seeds in true seed propagated species;

(6) Strategies for seed collection and propagation with the view of population genetics for the conservation of genetic diversity, especially on outcrossing polyploids;

(7) Databases for plant pathogens and pests including biology, epidemics, diagnostics and protection methods, a molecular plant $\mathrm{x}$ pathogen/pest interaction, chemical ecology and integrated pest management should be emphasized on the basis of sustainable industrial production based on resistant cultivars and management methods based on them;

(8) Screening methods for chemical components, particularly for pharmacognotic uses; and

(9) Transformation processes and cost-down for new industrial materials such as bio-degradable plastics made of plants.

\subsection{International collaborations and networking on} plant genetic resources with biotechnology applications

So far, we have discussed the role of biotechnology in the conservation of plant genetic resources and their enhanced utilization for crop improvement. We have also stated briefly the various technologies available which can help either in single application or in combination for plant improvement workers to achieve results that have not been possible through conventional techniques, or which used to take long periods. One major theme that can be seen through all the discussion is the multidisciplinary nature of both biotechnology and plant genetic resources. They are both made up of a number of sometimes overlapping disciplines. Such a multidisciplinary nature requires excellent cooperation among all concerned for the successful use of the tools for utilization of the resources available. This is especially true when the issue of transfer of technology is concerned. To make the transfer more effective and to ensure equitable sharing of profits, a multilateral collaboration is more desirable. This logically leads us to networking. We will discuss a couple of examples here of how such networking can be taken forward, in relation to plant genetic resources and their utilization. However, it must be noted that the networks under consideration are not those formulated for biotechnology work but for genetic resources management purposes. Within this scope, efforts are under way to link up the network members in using biotechnological tools for the study and use of genetic resources.
The International Plant Genetic Resources Institute (IPGRI), with financial support from the government of Japan, is an active partner in the International Network on Bamboo and Rattan (INBAR) and is mainly concerned with the PGR aspects of INBAR through its Working Group on Biodiversity and Genetic Resources. Here we consider rattans or canes, which are unique group of climbing palms in tropical rain forests. There are more than 600 species in 13 genera, Calamus (400 species) and Daemonorops (115 species) being the largest [41]. Millions of people in the tropics depend on rattans for their livelihood. As there are numerous species of rattan it is not possible to work on all of them. Some level of prioritization is required to undertake activities on rattan plant genetic resources conservation and use. Initially the species on which work will be carried out is determined [41], through consultation of the network members, assisted by resource persons. Along with priority species, some activities were identified, including assessment of the status of rattan genetic resources, assessment of the degree of threat of genetic erosion, conservation priorities and the development of a database with applications of modern biotechnology. There is need for a clear taxonomy and a simple practical key for species of economic importance. Studies focusing on genecological variation and genetic diversity are in progress, with possible linking with training. Ethnobotanical studies focusing on the traditional knowledge and management of rattan need to be developed. Assisting in exploration and collecting of rattan and conduct of ecogeographic studies are essential. There is a need to develop technology for long-term conservation and utilization, including in vitro culture methods for $e x$ situ conservation [41]. Development of sustainable in situ conservation strategies for these species is another area that needs urgent consideration. This would require an assessment of in situ diversity using molecular markers before such methods could be used for improvement purposes. Within the network of INBAR, in partnership with national programs such as Thailand, and linkages with advanced institutes in Sweden, IPGRI is supporting the study of genetic diversity in rattan [42].

Other examples are International Coconut Genetic Resources Network (COGENT), INIBAP (International Network for the Improvement of Banana and Plantain) and SGRP (System-wide Genetic Resources ProgrammeCGIAR) which are under auspices of IPGRI or joint coordination by IPGRI and sister International Agricultural Research Centers/International Genebanks [17, 31]. These mentioned networks represent well the national and international communities that share information, activities and common concerns. A USA based alliance made mainly of universities, GREAN (Global Research on the Environmental and Agricultural Nexus for the 21st Century) has strong connections with the above networkings by providing research opportunities for graduate students and university faculty members and direct human resources contribution from their higher education programs [43].

On the other hand, irrespective of the amount of financial contribution made to these networks from Japan 
mainly via the Ministry of Foreign Affairs, there is very little human resources contribution to these international networkings. However, it should be recognized that JIRCAS, Japan International Research Center for Agricultural Sciences, and JICA, Japan International Cooperation Agency, have their own bilateral activities on PGR, and they may be the best starting points for the international efforts. Also an academic institution based initiative may be coming out as the precinct activities under "Research for the Future Program" (RFTF) which is financially supported by Japan Society of Promotion of Sciences (JSPS). Not only the critics of the present weakness, an encouragement should be made to academic/ public and private sectors in Japan to eliminate the exploitation of the PGR in industrial utilization. In considering the past contribution, overall future values and the specific industrial potentials of the PGR, the private sector which uses the PGR for their own business and profit should contribute and share the benefits in lights of global needs. For conceptual guidance on such international collaborations shall be referred to Bunting [44], Iwanaga [45] and Tompson [46].

\section{Acknowledgments}

This paper is a short version made of essential contexts from Watanabe[47], Watanabe et al. [11] and a text from Future Harvest Campaign [8].

KNW acknowledges the Research for the Future (RFTF) Program under the Japan Society for the Promotion of Sciences (JSPS), project \# JSPS-RFTF96L00603 in the partial support on writing this article. Valuable information was greatly provided by International Plant Genetic Resources Institute (IPGRI) and its mother frame organization, Consultive Group on International Agricultural Research (CGIAR). KNW also thanks Japan Bioindustry Association (JBA) and International AgriBiotechnology Association of Japan (IABA-J) for their morale support for the preparation of this manuscript.

\section{References}

[1] Maxted, N., Ford-Lloyd, B.V., Hawkes, J.G., (eds.) 1997. "Plant Genetic Conservation-The In situ Approach", Chapman and Hall, London, UK.

[2] Chrispeels, M.J., Sadava, D.E., 1994. "Plants, Genes, and Agriculture”, Johns and Bartlett Publ., Boston, MA, USA.

[3] Harlan, J.R., 1992. "Crops and Man", American Society of Agronomy and Crop Science Society of America, Madison, WI, USA.

[4] Eyzaguierre, P., Iwanaga, M., (eds.) 1997. "Participatory Plant Breeding", IPGRI, Rome, Italy.

[5] Buxton, D.R., Shibles, R., Forsberg, R.A., Blad, B.L., Asay, K.H., Paulsen, G.M., Wilson, R.F., (eds.) 1993. "International Crop Science I", CSSA, Madison, WI, USA.

[6] Hawkes, J.G., 1983. "The Diversity of Crop Plants", Harvard University Press, Boston, US.

[7] Brown, A.H.D., Clegg, M.T., Kahler, A.L., Weir, B.S., 1990. "Plant Population Genetics, Breeding and Genetic Resources", Sinauer Associates Inc., Sunderland, MA, USA.

[8] CGIAR 1998. In "Future Harvest" Consultive Group on
International Agricultural Research, Washington, D.C. http://www.futureharvest.org

[9] Watanabe, K.N., Raman, K.V., 1997. In "Plant Biotechnology and Plant Genetic Resources for Sustainability and Productivity" (eds. by Watanabe, K.N., Pehu, E.), p. 1-13, RG Landes, Austin, TX, USA.

[10] Altman, D.W., Watanabe, K.N., 1995. "Plant Biotechnology Transfer to Development Countries", RG Landes, Austin, TX, USA.

[11] Watanabe, K.N., Rao, R., Iwanaga, M., 1998. Plant Biotechnology, 15: 115-122.

[12] Raven, P.H., 1992. In "Biodiversity: the Foundation of Biotechnology. US-EC Workshop-Biotechnology and Genetic Resources”, p. 1-3, Airlie, VA, USA.

[13] Shiva, H., 1994. UNESCO/Environmental Education Dossiers 9: 2-3.

[14] Price, S.C., 1995. In "Conservation of Plant Genes" (eds. by Adams, R.P., Adams, J.E.), p. 45-67, Academic Press, San Diego, CA, USA.

[15] Busch, L., 1995. Biotechnology and Development Monitor, 24.

[16] Stähler, F., 1994. Ecol. Econ., 11: 227-236.

[17] Rao, V.R., Iwanaga, M., 1997. In "Plant Biotechnology and Plant Genetic Resources for Sustainability and Productivity" (eds. by Watanabe, K.N., Pehu, E.), p. 29-69, RG Landes, Austin, TX, USA.

[18] Ford-Lloyd, B., Jackson, M., 1986. "Plant Genetic Resources: An Introduction to Their Conservation and Use", Edward Arnold, London, UK.

[19] Hodgkins, T., Brown, A.H.D., van Hintum, Th., J.L., Morales, E.A.V., (eds.) 1995. "Core Collections of Plant Genetic Resources”, John Wiley \& Sons, Clichester, UK.

[20] Adams, R.P., Adams, J.E., (eds.) 1992. "Conservation of Plant Genes”, Academic Press, New York, USA.

[21] Gustafson, J.P., Appels, R., Raven, P., (eds.) 1993. Gene Conservation and Exploitation", Plenum Press, New York, USA.

[22] Solbrig, O.T., van Emden, H.M., van Oordt, P.G.W.G., (eds.) 1994. "Biodiversity and Global Change", C.A.B. International, Wallingford, UK.

[23] National Research Council, 1991. "Managing Global Genetic Resources-Forest Trees", National Academy Press, Washington, D.C., USA.

[24] National Research Council, 1993. "Managing Global Genetic Resources-Agricultural Crop Issues and Policies", National Academy Press, Washington, D.C., USA.

[25] Brown, A.H.D., Frankel, O.H., Marshall, D.R., Williams, J.T., 1989. "The Use of Plant Genetic Resources", Cambridge University Press, London, UK.

[26] Leskien, D., Flitner, M., 1997. "Intellectual Property Rights and Plant Genetic Resources: Options for a Sui Generis System", IPGRI, Rome, Italy.

[27] Consultive Group on International Agrucltureal Research (CGIAR), 1997. "Ethics and Equity-in conservation and use of genetic resources for sustainable food security", IPGRI, Rome, Italy.

[28] Lesser, W.H., 1997. In "Plant Biotechnology and Plant Genetic Resources for Sustainability and Productivity" (eds. by Watanabe, K.N., Pehu, E.), p. 71-78, RG Landes, Austin, TX, USA. 
[29] Barton, J.H., 1998. In "Intellectual Property Rights in Agricultural Biotechnology” (eds. by Erbisch, F.H., Maredia, K.M.), p. 19-30, C.A.B. International, Wallingford, UK.

[30] Watanabe, K.N., Komamine, A., Nishizawa, Y., 1998. In "Intellectual Property Rights in Agricultural Biotechnology" (eds. by Erbisch, F.H., Maredia, K.M.), p. 117-127, C.A.B. International, Wallingford, UK.

[31] Watanabe, K.N., Iwanaga, M., 1997. Bioscience \& Bioindustry, 55: 732-735. (In Japanese).

[32] Anonymous, 1997. Special Report: CBD/COP-3. Diversity 12 (4).

[33] Watanabe, K.N., Chisaki, O., 1998. Bioscience \& Bioindustry, 56: 267-269. (In Japanese).

[34] GRAIN, 1997. "Patenting, Piracy and Perverted Promises", June 12, 1997, http:// www/igc.apc.org/bionet

[35] Baenziger, P.S., Kleese, R.A., Barnes, R.F., (eds.) 1993. "Intellectual Property Rights: Protection of Plant Materials", Crop Science Society of America, Madison, WI, USA.

[36] Lesser, W.H., 1997. "The Role of Intellectual Property Rights in Biotechnology Transfer Under the Convention of Biological Diversity", International Service for Acquisition of Agri-Biotechnology Applications, Ithaca, NY, USA.

[37] Pistorius, R., 1997. "Scientists, Plants and Politics", IPGRI, Rome, Italy.

[38] Ouédraogo, A.S., Poulsen, K., Stubsgaard, F., (eds.) 1996. "Intermediate/Reculcitrant Tropical Forest Tree Seeds", IPGRI, Rome, Italy.
[39] Ayad, W.G., Hodgkin, T., Jaradat, A., Rao, V.R., (eds.) 1997. "Molecular Genetic Techniques for Plant Genetic Resources”, IPGRI, Rome, Italy.

[40] Karp, A., Kresovich, S., Bhat, K.V., Ayad, W.G., Hodgkin, T., 1997. "Molecular Tools in Plant Genetic Resources Conservation: A Guide to the Technologies", IPGRI, Rome, Italy.

[41] Rao, V.R., Rao, A.N., 1996. "Bamboo and Rattan Genetic Resources and Use”, IPGRI, Rome, Italy.

[42] Changtragoon, S., Szmidt, A.E., Wang, X-R., 1995. In "Molecular Genetic Techniques for Plant Genetic Resources” (eds. by Ayad, W.G., et al.), IPGRI, p. 39-43, IPGRI, Rome, Italy.

[43] Anonymous, 1995. "Global Research on the Environmental and Agricultural Nexus for the 21st Century", University of Florida, Gainsville, USA.

[44] Bunting, A.H. 1995. In "Plant Biotechnology Transfer to Developing Countries" (eds. by Altman, D.W., Watanabe, K.N.), p. 3-20, R.G. Landes, Austin, USA.

[45] Iwanaga M., 1992. In “International Crop Science I" (eds. by Buxton, D.R., et al.), p. 407-413, Crop Science Society of America, Madison, WI, USA.

[46] Tompson, P.B., 1992. "The Ethics of Aid and Trade", Cambridge University Press, London, UK.

[47] Watanabe, K.N., 1999. In "Genetically Engineered Plants -Future and Shades-(provisional title)” (ed. By Sano, H.), Gakkai Syuppan Center, Tokyo, Japan. (In preparation). 